\title{
Serum immunoglobulin $E$ response as a marker for unfavorable prognosis following cholesteryl pullulan-MAGE A4 vaccination
}

\author{
TAKEHIRO ABIKO ${ }^{1}$, TAKAHIRO TSUCHIKAWA $^{1}$, KENGO MIYAUCHI $^{1}$, MASATAKA WADA $^{1}$, \\ NORIAKI KYOGOKU ${ }^{1}$, TOSHIAKI SHICHINOHE ${ }^{1}$, YOSHIHIRO MIYAHARA ${ }^{2}$, SHINICHI KAGEYAMA ${ }^{2}$, \\ HIROAKI IKEDA $^{3}$, HIROSHI SHIKU ${ }^{2}$ and SATOSHI HIRANO ${ }^{1}$ \\ ${ }^{1}$ Department of Gastroenterological Surgery II, Division of Surgery, Hokkaido University Graduate School of Medicine, \\ Sapporo, Hokkaido 060-8638; ${ }^{2}$ Department of Immuno-Gene Therapy, Mie University Graduate School of Medicine, \\ Tsu, Mie 514-8507; ${ }^{3}$ Department of Oncology, Nagasaki University Graduate \\ School of Biomedical Sciences, Nagasaki 852-8521, Japan
}

Received November 4, 2016; Accepted November 7, 2017

DOI: $10.3892 / \mathrm{ol} .2018 .7767$

\begin{abstract}
Since 2009, a cancer vaccine clinical trial was conducted with melanoma antigen gene-A4 as an immunogenic agent. The levels of IgG1, IgG2 and IgG3, which are known to be Type 1 Thelper cell-associated antibodies, and the levels of IgG4 and IgE, which are known to be Type 2 T helper cell-associated antibodies, were measured and used as biomarkers for predicting therapeutic effect. The results of the present study indicated a strong positive correlation between $\mathrm{IgG} 2$ and $\mathrm{IgG} 4$, with a correlation coefficient of $\mathrm{R}=0.808(\mathrm{P}<0.0001)$. The survival time of patients in which $\mathrm{IgE}$ responses were induced was significantly shorter compared with the survival time of patients with no IgE induction. The results of the present study suggest that caution is required when antigen-specific $\mathrm{IgE}$ responses are induced during cancer vaccination therapy.
\end{abstract}

\section{Introduction}

Multimodal treatment consisting of surgery, chemotherapy and radiotherapy is used to treat advanced, recurrent cancer patients, yet a definitive cure remains difficult to achieve. However, a new treatment method, cancer immunotherapy, which uses the host's immune system to fight against cancer, is being researched and developed. Tumor antigens recognized by CD8-positive cytotoxic $\mathrm{T}$ lymphocytes ( $\mathrm{T}$ cells) were discovered in the 1990s (1). This discovery has advanced the development of cancer-specific immunostimulatory treatments, including cancer vaccine therapy, adoptive immune cell therapy

Correspondence to: Dr Takahiro Tsuchikawa, Department of Gastroenterological Surgery II, Division of Surgery, Hokkaido University Graduate School of Medicine, North 15, West 7, Sapporo, Hokkaido 060-8638, Japan

E-mail: tsuchi0108@gmail.com

Key words: melanoma antigen gene-A4, vaccine, antibody response, immunoglobulin subclass, immunoglobulin $\mathrm{E}$ and antibody therapy (2). Immunotherapy studies in animal models have demonstrated induction of tumor antigen-specific immunity and antitumor effects. However, Rosenberg et al (3) reported that only a response rate of a few percent has been demonstrated in human clinical trials. Multiple immune escape mechanisms, including the presence of immunosuppressive cells, loss of human leukocyte antigen (HLA) class I antigens and immunological tolerance, have been suggested as possible causes of the low efficacy of immunostimulatory treatments in humans. Therefore, combined cancer vaccines and adjuvant immunotherapies, including OK-432 and poly-ICLC is widely performed to enhance its effect. Furthermore, OK-432 has been reported to enhance the effect of chemotherapy (4), while poly-ICLC has been reported to rapidly and potently induce NY-ESO-1-specific immune responses (5).

Since 2009, in search of biomarkers for predicting therapeutic effect, a cancer vaccine clinical trial has been conducted with the cancer antigen, melanoma antigen gene-A4 (MAGE-A4), using the full-length protein as an immunogenic agent (clinical trial registration no. UMIN000001999). Numerous studies have used antigen-specific humoral immune response as a biomarker for cancer vaccines (6-8). However, the majority of these studies have only evaluated IgG antibodies directed against an immunogenic agent. To the best of our knowledge, there are no studies that have reported on biomarkers that reflect therapeutic effect. From the beginning of the cancer vaccine clinical trial, the levels of $\mathrm{IgG}$ subclass (IgG1, IgG2, IgG3 and IgG4) and IgE antibodies were measured and used as biomarkers for predicting therapeutic effect. Antigen-specific IgG1, IgG2 and IgG3 antibodies are produced by B lymphocytes (B cells) when the type $1 \mathrm{~T}$ helper (Th1) cell-mediated immune response, including tumor immunity, is favored. Antigen-specific IgG4 and IgE antibodies are produced by B cells when the type $2 \mathrm{~T}$ helper (Th2) cell-mediated humoral immune response, including allergic reactions, is favored $(9,10)$. Therefore, IgG1, IgG2 and IgG3 were classified as Th1-associated antibodies, while IgG4 and IgE were classified as Th2-associated antibodies.

The objective of the present study was to assess the effects of cancer vaccination on the Th1-associated MAGE-A4 
specific antibodies $\operatorname{IgG} 1, \operatorname{IgG} 2$ and $\operatorname{IgG} 3$ as well as on Th2-associated MAGE-A4 specific antibodies IgG4 and IgE, in patients vaccinated with the cancer vaccine. This was evaluated by measuring: i) Levels of MAGE-A4 specific IgG subclass and IgE antibodies as biomarkers and ii) time-course changes of the antigen-specific humoral immune response using enzyme-linked immunosorbent assay (ELISA).

\section{Materials and methods}

Study design. The clinical trial was an open-label trial. The subjects of this trial were patients with locally advanced, recurrent or metastatic tumors that were histologically confirmed as malignant and were resistant to standard therapy. Eligibility criteria were as follows: i) Patients with tumors expressing MAGE-A4 antigen, assessed by immunohistochemistry; ii) an Eastern Cooperative Oncology Group performance status of $0-2$ (11); iii) an age of $\geq 20$ years; iv) $>4$ months survival expected; v) adequate bone-marrow, cardiac, pulmonary, hepatic and renal functions; and vi) the patient had no desire to become pregnant. Exclusion criteria were as follow: i) Positive for human immunodeficiency virus antibody; ii) multiple malignant diseases; iii) concurrent autoimmune disease; iv) a past history of anaphylaxis; v) active metastasis to the central nervous system; vi) concurrent anticancer therapy during the 4 weeks prior to the initiation of the trial (except with an anticancer drug that does not require drug breaks or hormone agents), including systemic steroids, immunosuppressive agents, irradiation or surgery for primary lesions; vii) pregnancy or breastfeeding and viii) a decision by the principal investigator or physician in charge that the patient was unsuitable. The patient recruitment began in August 2009 and ended in March 2013. It was confirmed that the patients' tumors expressed the MAGE-A4 antigen, which was assessed using immunohistochemistry (IHC), as described later. The patients were divided into 3 groups in the order of registration: Group 1 patients $(n=3)$ received $100 \mu \mathrm{g}$ cholesteryl pullulan (CHP)-MAGE-A4 vaccine; group $2(\mathrm{n}=3)$ received $300 \mu \mathrm{g}$ CHP-MAGE-A4 vaccine; group 3 $(\mathrm{n}=12)$ received $300 \mu \mathrm{g}$ CHP-MAGE-A4 vaccine and $50 \mu \mathrm{g}$ OK-432 (Chugai Pharmaceutical Co., Ltd., Tokyo, Japan) that was used as an immune adjuvant. Patients were injected subcutaneously for a total of 6 cycles at 2-week intervals (one injection per one cycle). Complete written informed consent was obtained from all patients at the time of enrollment. The study was approved by the Ethics Committee of Hokkaido University Graduate School of Medicine (Sapporo, Japan). Patient characteristics of the patients in Groups 1 and 2 were reported previously (12).

Evaluation of clinical responses. To evaluate the clinical response, computed tomography (CT) scans were taken prior to the first vaccination and after the fourth vaccination. All measurable lesions were classified using the modified Response Evaluation Criteria in Solid Tumors (mRECIST). mRECIST are original criteria consisting of adaptations to the RECIST based upon the recommendations of the Cancer Vaccine Clinical Trial Working Group (13). mRECIST were as follows: i) Complete response (CR), disappearance of all target lesions; ii) partial response (PR), compared with the sum of the largest diameters of the target lesions at the time of registration in this trial, the total sum of the largest diameters of the target lesions, new target lesions and non-target lesions (increased to $\geq 10 \mathrm{~mm}$ ), decreased by $\geq 30 \%$; iii) stable disease (SD), tumor shrinkage is inadequate to be PR and tumor growth is insufficient to be progressive disease (PD), compared with the minimum sum of the largest diameters of the target lesions following treatment; and iv) PD, compared with the minimum sum of the largest diameters of target lesions following treatment, the total sum of the largest diameter of target lesions, new lesions and non-target lesions (increased to $\geq 10 \mathrm{~mm}$ ), increased by $\geq 20 \%$. mRECIST do not provide a PD classification when new lesions appear alone.

Subject patients of the study. The subjects of the present study were the 12 patients who were enrolled in group 3 .

Serum samples. Patient peripheral blood was collected prior to the initial vaccination (baseline), at 2 weeks after each subsequent vaccination and at 4 weeks after the last (6th) vaccination. Plasma was collected using EDTA as an anticoagulant and was centrifuged for $6 \mathrm{~min}$ at $240 \mathrm{x} \mathrm{g}$ at $18^{\circ} \mathrm{C}$. The supernatant was then centrifuged for $10 \mathrm{~min}$ at $670 \mathrm{xg}$ at $4^{\circ} \mathrm{C}$. Plasma was then stored at $-80^{\circ} \mathrm{C}$ until analysis.

Preparation of CHP-MAGE-A4. Full length MAGE-A4 cDNA was cloned into a pET vector (ImmunoFrontier, Inc., Tokyo, Japan) and introduced into Escherichia coli. Expression of His-MAGE-A4 protein was induced by the addition of isopro pyl-L-thio- $\beta$-D-galactopyranoside to the bacterial cell culture; produced protein was recovered and highly purified using a combination of chromatographic techniques, including metal chelating affinity, anion exchange, size exclusion and hydroxyapatite chromatography. CHP was synthesized by a chemical reaction between pullulan (average molecular weight, $100 \mathrm{kDa}$ ) and cholesterol isocyanate in pyridine/dimethyl sulfoxide solution (Nippon Oil and Fats Co., Ltd., Tokyo, Japan). After purification by extraction and precipitation, resultant CHP was emulsified in water and subsequently freeze-dried. When redissolved in water or buffers, CHP spontaneously forms nanoparticles (14-17). These nanoparticles (20-50 nm) contain the hydrophobic domains of cholesterol groups internally, which associate with hydrophobic regions of the MAGE-A4 protein, forming a stable complex in solution (14-17). This complex of protein and CHP was used as the CHP-MAGE-A4 vaccine. These vaccines were produced by ImmunoFrontier, Inc. (Tokyo, Japan) and kindly provided by the Department of Immuno-Gene Therapy at Mie University Graduate School of Medicine (Tsu, Japan).

Detection of MAGE-A4 expression in tumors. To investigate MAGE-A4 antigen expression in tumors to determine whether patients could be enrolled in the present study, each patient's formalin-fixed (in 10-15\% formalin overnight at room temperature), paraffin-embedded tissue sections (thickness, $1.5 \mu \mathrm{m}$ ) were subjected to IHC analysis. These tissues were provided by the hospital where patient had previously received treatment. Immunohistochemical reactions were performed using the streptavidin-biotin-peroxidase method (18). The primary antibody, molluscum contagiosum 
virus 1 (MCV-1; $2.8 \mathrm{mg} / \mathrm{ml})$, provided by Mie University, was used diluted to 1:2,000 in Dako Antibody Diluent and Protein Block Serum-Free (Dako; Agilent Technologies, Inc., Santa Clara, CA, USA). MCV-1 is a monoclonal antibody generated in mice immunized with a human MAGE-A4 recombinant protein. Archival tissue sections were deparaffinized in xylene, and rehydrated in a graded series of ethanol solutions. After washing in deionized water, antigens were unmasked by incubation for $7 \mathrm{~min}$ with citric acid buffer $(\mathrm{pH} 6.0)$ in a pressure cooker at $120^{\circ} \mathrm{C}$. After washing in deionized water, endogenous peroxidase activity was blocked by incubation for 5 min with $3 \%$ hydrogen peroxide in methanol at room temperature. After washing in deionized water and high-wash-PBS-T (pH 7.7, $0.44 \mathrm{M}$ $\mathrm{NaCl}, 0.1 \%$ Tween-20 in PBS), specimens were incubated overnight at $4^{\circ} \mathrm{C}$ with the primary antibody described above. After washing in high-wash-PBS-T, sections were incubated with peroxidase-labeled goat anti-mouse and anti-rabbit IgG (Fab') polyclonal antibody [Histofine Simple Stain MAX PO (MULTI); Nichirei Biosciences, Inc., Tokyo, Japan] for $30 \mathrm{~min}$ at room temperature. After washing in high-wash-PBS-T, immunohistochemical reactions were visualized with freshly prepared 3,3'-diaminobenzidine tetrahydrochloride (Histofine SAB-PO [M] kit; Nichirei Biosciences, Inc.). Subsequently, slides were counterstained with hematoxylin (undiluted solution) for $20 \mathrm{sec}$ at room temperature and mounted with coverslips. All slides were observed using a light microscope at magnifications of $\mathrm{x} 40$, $\mathrm{x} 100$ and $\mathrm{x} 400$.

If stained cells were observed, the specimen was labeled 'positive', regardless of the degree of positivity, or the localization of staining in the stained cells (nucleus, cytoplasm or nucleus and cytoplasm). MAGE-A4 expression was confirmed with positive identification by two physicians, one being a pathologist.

Detection of antibody responses to the MAGE-A4 protein. Specific whole IgG antibodies against MAGE-A4 in the sera were measured using ELISA. The MAGE-A4 recombinant protein in PBS was adsorbed onto immuno plates (442404; Nunc; Sigma-Aldrich; Merck KGaA, Darmstadt, Germany) at a concentration of $20 \mathrm{ng} / 50 \mu \mathrm{l} /$ well overnight at $4^{\circ} \mathrm{C}$. Plates were washed in PBS with $0.05 \%$ Tween-20 and were then blocked for $2 \mathrm{~h}$ at room temperature with $200 \mu \mathrm{l} /$ well $1 \%$ bovine serum albumin (Sigma-Aldrich; Merck KGaA) (BSA)/PBS. Serum samples were diluted 1:100, 1:400 and $1: 1,600$ in $1 \%$ BSA/PBS. After washing, $100 \mu 1$ serum/well was added as the primary antibody and was incubated overnight at $4^{\circ} \mathrm{C}$. After washing, $100 \mu \mathrm{l} /$ well of 1:4,000 diluted goat anti-human $\mathrm{IgG}(\mathrm{H}+\mathrm{L}$ chain)-horseradish peroxidase (HRP) (cat. no. 206; Medical \& Biological Laboratories Co., Ltd., Nagoya, Japan) in $1 \%$ BSA/PBS was added as the secondary antibody and was incubated for $5 \mathrm{~h}$ at $4^{\circ} \mathrm{C}$. Plates were washed and incubated with $100 \mu \mathrm{l} /$ well TMB Substrate (Pierce; Thermo Fisher Scientific, Inc., Waltham, MA, USA) for $3 \mathrm{~min}$ at room temperature. Subsequently, $100 \mu \mathrm{l} /$ well $0.18 \mathrm{M}$ $\mathrm{H}_{2} \mathrm{SO}_{4}$ was added and the optical density (OD) of the sample was immediately read in a microplate spectrophotometer at a wavelength of $450 \mathrm{~nm}$ (SpectraMax 190; Molecular Devices, LLC, Sunnyvale, CA, USA). The cutoff OD 450 absorption value was calculated according to the following equation: Cutoff value $=$ mean $O D$ value of a 1:400 diluted pooled serum sample from healthy donors $(n=24)+1.645 x$ standard deviation (SD). The cutoff value was determined to be 0.288 . Similarly, healthy donor sera were used as controls to correct errors in every examination and patients' OD values were corrected using the resultant calculated error ratios. The healthy donors comprised doctors and other medical staff from the department of Gastroenterological Surgery II, Division of Surgery, Hokkaido University Graduate School of Medicine, Sapporo, Japan (age range, 20-60 years; 18 male and 6 female). Healthy donor accrual began and finished in April 2009. Written informed consent was obtained from these donors.

For cases with negative serum response before vaccination (referred to as 'baseline negative' hereafter), positivity was defined when OD values of the serum samples at 400 -fold dilution exceeded the aforementioned cutoff value before the end of the 6th vaccination. For cases with positive serum response before vaccination (referred to as 'baseline positive' hereafter), positivity was defined when OD values of the serum samples at 400 -fold dilution increased by $>100 \%$ before the end of the 6 th vaccination.

Detection of IgG subclass antibody responses to the MAGE-A4 protein. The IgG subclass antibody response to the MAGE-A4 protein was detected with ELISA using the aforementioned method. The secondary antibodies were polyclonal sheep anti-human IgG1 (dilution, 1:25,600; cat. no. AP006), IgG2 (dilution, 12,800; cat. no. AP007), IgG3 (dilution, 1:12,800; cat. no. AP008) and IgG4 (dilution, 1:12,800; cat. no. AP009) (H+L chain)-HRP (Binding Site, Birmingham, UK).

The following cutoff values of IgG subclass antibodies were calculated using the aforementioned method: IgG1, 0.192; IgG2, 0.140; IgG3, 0.076; and IgG4, 0.004. Similarly, healthy donor plasma samples were used as controls to correct errors in every examination, and patient OD values were corrected using the resultant calculated error ratios.

As in the aforementioned method, positivity in baseline negative cases was determined when OD values exceeded the cut-off values before the end of the 6th vaccination. Likewise, positivity in baseline positive cases was determined when OD values increased by $>100 \%$ before the end of the sixth vaccination.

In all of the tests, the serum samples of the three aforementioned donors close to the median OD value, collected while calculating the cutoff value, were used as controls. For IgG1 and $\operatorname{IgG} 2$, the OD values were adjusted according to the error ratio.

The OD values of IgG subclass antibodies are lower compared with the OD values of IgG when the dilution concentration of the patient's serum samples is the same. Therefore, the calculation of the $\operatorname{IgG}$ subclass cutoff value and the post-vaccination evaluation were conducted using OD values of serum samples at 100-fold dilution.

Detection of IgE antibody responses to the MAGE-A4 protein. Specific IgE antibodies against MAGE-A4 in the plasma were measured using ELISA, according to the aforementioned method, with the following differences: As the primary antibody, the collected plasma samples were diluted 
Table I. Patient characteristics.

\begin{tabular}{|c|c|c|c|c|c|c|c|c|c|c|c|}
\hline \multirow[b]{2}{*}{ Case } & \multirow[b]{2}{*}{ Sex } & \multirow{2}{*}{$\begin{array}{l}\text { Age, } \\
\text { years }\end{array}$} & \multirow[b]{2}{*}{ Tumor type } & \multicolumn{6}{|c|}{ Anti MAGE-A4 antibody response } & \multirow{2}{*}{$\begin{array}{c}\text { Clinical } \\
\text { response } \\
\text { (mRECIST) }\end{array}$} & \multirow{2}{*}{$\begin{array}{c}\text { Survival } \\
\text { time after } \\
\text { vaccination, days }\end{array}$} \\
\hline & & & & $\operatorname{IgG}$ & IgG1 & $\operatorname{IgG} 2$ & $\operatorname{IgG} 3$ & IgG4 & $\operatorname{IgE}$ & & \\
\hline 1 & M & 62 & Colon $\mathrm{Ca}$ & + & + & + & + & + & + & PD & 96 \\
\hline 2 & $\mathrm{~F}$ & 63 & Breast $\mathrm{Ca}$ & & & & & & & PD & 88 \\
\hline 3 & $\mathrm{~F}$ & 48 & Pancreas $\mathrm{Ca}$ & + & + & & + & & & SD & 148 \\
\hline 4 & M & 79 & Bile duct $\mathrm{Ca}$ & $\mathrm{B}$ & & B & & & & SD & 470 \\
\hline 5 & M & 63 & Rectal Ca & $+\mathrm{B}$ & $+\mathrm{B}$ & + & $+\mathrm{B}$ & + & & SD & 469 \\
\hline 6 & M & 58 & Mesothelioma & + & + & & + & + & & SD & 509 \\
\hline 7 & M & 78 & Gallbladder $\mathrm{Ca}$ & + & + & + & $+\mathrm{B}$ & + & & SD & 141 \\
\hline 8 & M & 34 & Rectal Ca & + & B & & & + & & SD & 317 \\
\hline 9 & $\mathrm{~F}$ & 63 & Colon Ca & B & + & & B & & & SD & 255 \\
\hline 10 & M & 60 & Colon $\mathrm{Ca}$ & + & + & + & + & + & & PD & 257 \\
\hline 11 & M & 71 & Colon $\mathrm{Ca}$ & B & $+\mathrm{B}$ & & B & + & + & PD & 105 \\
\hline 12 & M & 71 & Colon $\mathrm{Ca}$ & + & + & + & + & + & & PD & 167 \\
\hline $\begin{array}{l}\text { Positive conversion } \\
\text { ratio, } \%\end{array}$ & & & & 66.7 & 75.0 & 41.7 & 58.3 & 66.7 & 16.7 & & \\
\hline
\end{tabular}

M, male; F, female; $\mathrm{Ca}$, cancer; $\mathrm{PD}$, progressive disease; $\mathrm{SD}$, stable disease; +, positive reaction; $\mathrm{B}$, baseline positive; MAGE, melanoma antigen gene-A4; mRECIST, modified response evaluation criteria in solid tumors.

from $1: 40$ to $1: 640$ in $1 \% \mathrm{BSA} / \mathrm{PBS}$. As the secondary antibody, $100 \mu \mathrm{l} /$ well of 1:1,000 diluted rabbit polyclonal anti-human IgE (A0094; Dako; Agilent Technologies, Inc.) in $1 \% \mathrm{BSA} / \mathrm{PBS}$ was added and incubated for $5 \mathrm{~h}$ at $4^{\circ} \mathrm{C}$. After washing, $100 \mu \mathrm{l} /$ well of 1:100 diluted goat polyclonal anti-rabbit immunoglobulin (K1491; EnVision kit-HRP; Dako; Agilent Technologies, Inc.) in 1\% BSA/PBS was added as a tertiary antibody. Samples were incubated for $40 \mathrm{~min}$ at room temperature. After washing, the OD was measured as described above. Since there were non-specific reactions in the negative control wells, the evaluation of IgE was performed qualitatively rather than quantitatively. Specific IgE antibodies were considered to be positive when the OD values of 40 -fold diluted serum samples following vaccination were $>150 \%$ of the OD values of baseline serum sample.

Statistical analysis. Data are presented as the median (range). Correlation was assessed using Pearson's product-moment correlation coefficient. The degree of correlation was determined according to the absolute value of the correlation coefficient $\mathrm{R}$ as follows: No correlation, $0 \leq \mathrm{R}<0.2$; weak correlation, $0.2 \leq \mathrm{R}<0.4$; moderate correlation, $0.4 \leq \mathrm{R}<0.7$ and strong correlation, $0.7 \leq \mathrm{R}<1.0$. The Kruskal-Wallis test followed by a Games-Howel post hoc test was used to detect significant differences between the ELISA results. The Kaplan-Meier method was used to estimate overall survival and survival differences were analyzed by the log-rank test. $\mathrm{P}<0.05$ was considered to indicate a statistically significant difference. All statistical analyses were performed using StatView J version 5.0 (SAS Institute, Inc., Cary, NC, USA) and Microsoft Excel 2011 (Microsoft Corporation, Redmond, WA, USA).

\section{Results}

Patient characteristics. For the purpose of matching the administration conditions (dose of CHP-MAGE-A4 and presence or absence of OK-432) of the cancer vaccine, the focus of the present study was limited to the 12 patients in group 3. Patient characteristics are presented in Table I. There were 12 patients ( 9 males and 3 females) who were diagnosed with locally advanced, recurrent or metastatic tumors that were histologically confirmed as malignant and that were resistant to standard therapy (7 colorectal, 1 breast, 1 pancreas, 1 bile duct, 1 malignant mesothelioma and 1 gallbladder). The median age was 63 years (range, 34-79 years).

Time-dependent transition of MAGE-A4-specific antibody responses. The positive conversion rates of anti-MAGE-A4 IgG subclass and anti-MAGE-A4 IgE in the patient serum samples at the time of completing the 6th vaccination are presented in Table I. The positive rate of Th1-associated antibodies IgG1, IgG2 and IgG3 was 75\% (9/12), 41.7\% (5/12) and 58.3\% (7/12), respectively. The positive rate of Th2-associated antibodies IgG4 and $\operatorname{IgE}$ was $66.7 \%(8 / 12)$ and $16.7 \%$ (2/12), respectively. Th1and Th2-associated antibodies were induced together in 7 cases (patients 1, 5, 6, 7, 10, 11 and 12); only Th1-associated antibodies were induced in 2 cases (patients 3 and 9); only Th2-associated antibodies were induced in 1 case (patient 8); neither Th1- nor Th2-associated antibodies were induced in 2 cases (patients 2 and 4; Table I). The pre- and post-vaccination time-dependent changes of OD values obtained with ELISA for each IgG subclass of antibodies were examined using the Kruskal-Wallis test followed by the Games-Howel post hoc test. There was a significant increase in the OD values of $\mathrm{IgG} 1$ following the completion of the scheduled vaccinations ( $\mathrm{P}=0.0001$; Fig. 1). 

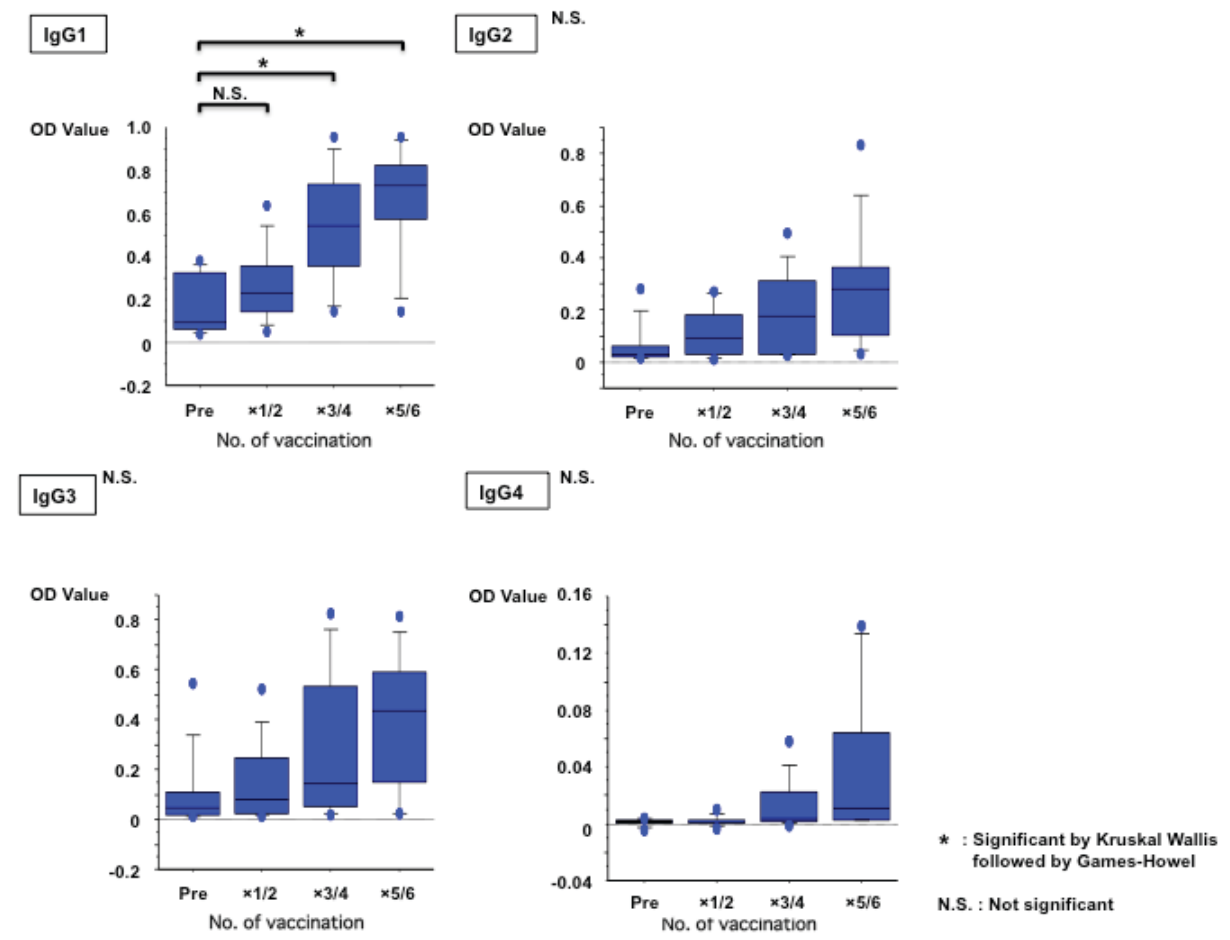

Figure 1. Time-dependent transition of melanoma antigen gene-A4-specific antibody responses. Pre- and post-vaccination time-dependent changes of OD values obtained with ELISA were examined using the Kruskal-Wallis test followed by the Games-Howel post hoc test. There was a significant increase in OD values for IgG1 following the completion of the scheduled vaccinations. "P $<0.05$. Pre, pre-vaccination; x1/2, after 1st and 2nd vaccinations; $\mathrm{x} 3 / 4$, after $3 \mathrm{rd}$ and 4 th vaccinations; $x 5 / 6$, after 5 th and 6 th vaccinations; N.S., not significant.
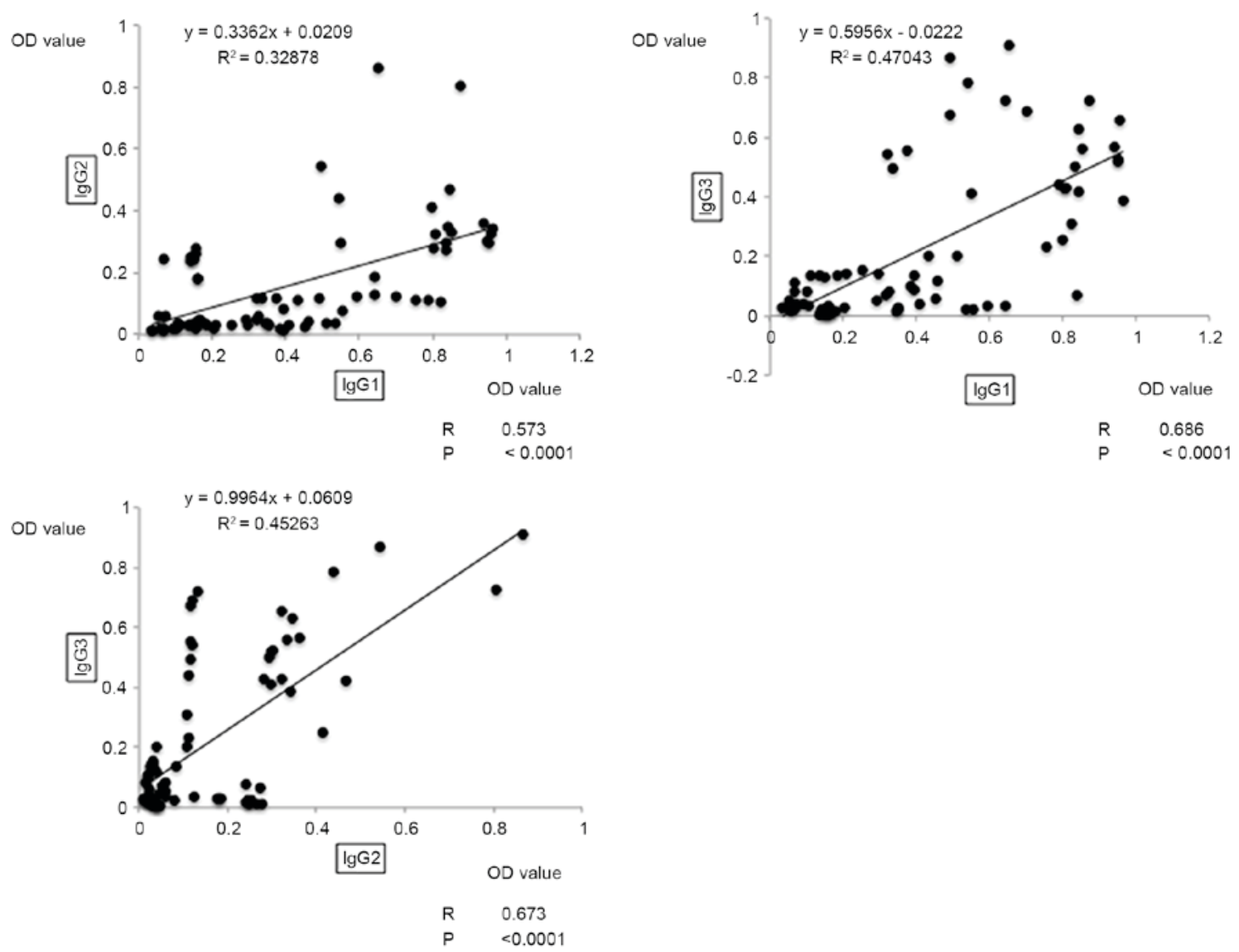

Figure 2. Correlations between Th1-associated antibody responses. Correlation analyses were performed for the OD values of Th1-associated antibodies. The number of points is 84 ( $\mathrm{n}=12$ and there were 7 lots of data per patient as these were obtained between pre-vaccination and the 6th vaccination). Th1, type $1 \mathrm{~T}$ helper cell. 

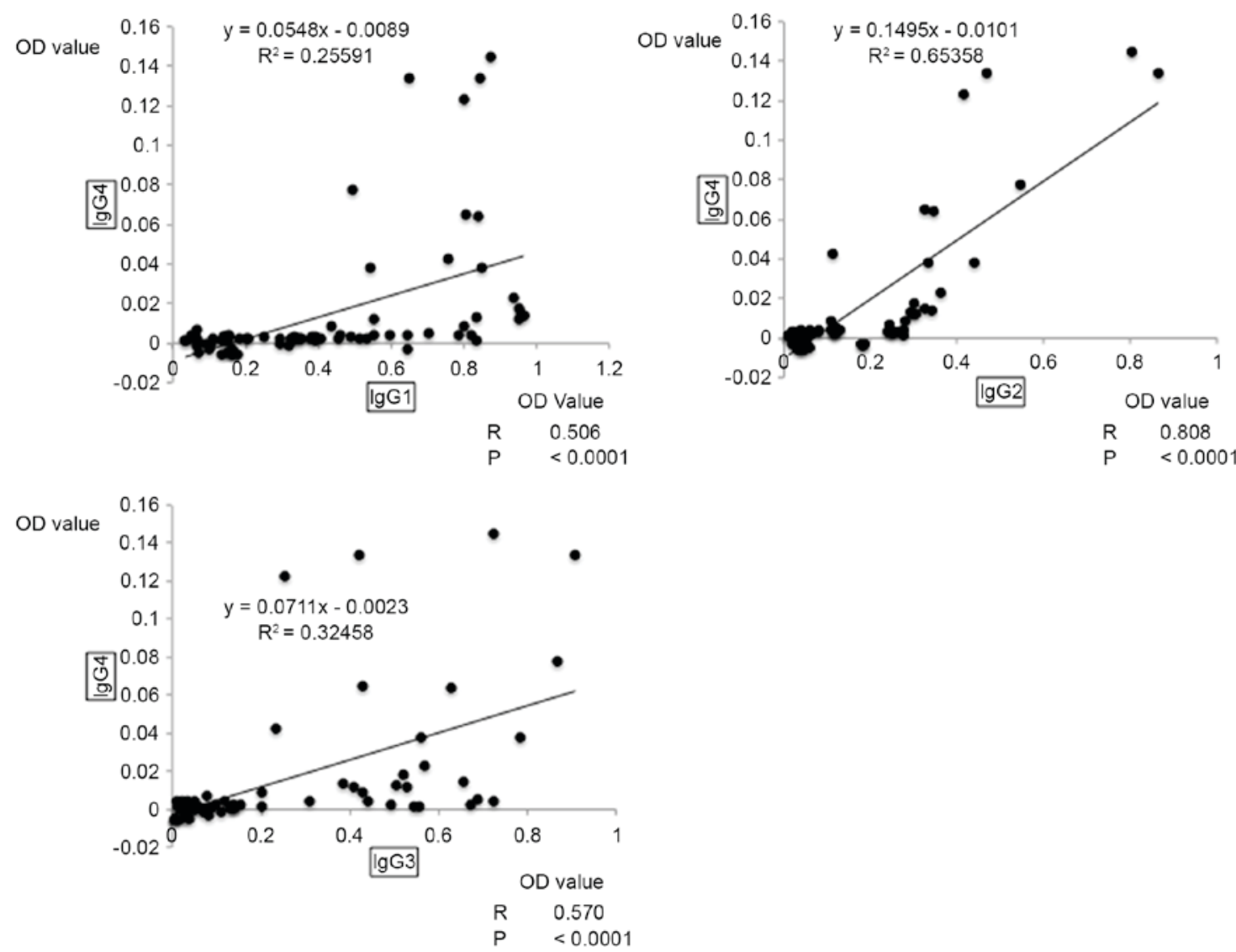

Figure 3. Correlations between Th1- and Th2-associated antibodies. Correlation analyses were performed for the OD values of antibodies associated with Th1 and $\mathrm{Th} 2$. The correlation coefficients between $\mathrm{IgG1}, \mathrm{IgG} 2$ and $\mathrm{IgG} 3 \mathrm{OD}$ values and the OD values of $\mathrm{IgG} 4$ were calculated. The number of points is 84 ( $\mathrm{n}=12$ and there were 7 lots of data per patient as these were obtained between pre-vaccination and the 6th vaccination). Th1, type $1 \mathrm{~T}$ helper cell; Th2, type $2 \mathrm{~T}$ helper cell.

The timing of the rise in antibody levels of the Th1-associated antibodies, IgG1, IgG2 and IgG3, is described below. Firstly, the median of the rising period for the 9 cases with increased IgG1 level was observed upon completion of the 3rd vaccination. Secondly, the median of the rising period for the 5 cases with increased $\operatorname{IgG} 2$ level was observed upon completion of the 2nd vaccination. Lastly, the median of the rising period for the 7 cases with increased IgG3 level was observed upon completion of the 4 th vaccination. For the Th2-associated antibodies, IgG4 and IgE, the median of the rising period for the 8 cases with increased IgG4 level was observed between the 4 th and 5 th vaccinations. The median of the rising period for the 2 cases with positive IgE response was observed upon completion of the 5th vaccination.

Correlations between antibody response patterns elicited by MAGE A4 vaccinations. The correlations between each of the antibodies in the patients' serum samples were examined using correlation analysis of OD values based on the ELISA results. Among the Th1-asssociated antibodies, the OD values of IgG1 and $\mathrm{IgG} 3$ presented the highest correlation, with a moderate positive correlation coefficient of $0.686(\mathrm{P}<0.0001$; Fig. 2). Additionally, a moderate positive correlation was observed between $\operatorname{IgG} 1$ and $\operatorname{IgG} 2(\mathrm{R}=0.573 ; \mathrm{P}<0.0001)$, and between IgG2 and IgG3 (R=0.673; P<0.001; Fig. 2). As for the OD values of antibodies associated with Th1 and Th2, a moderate positive correlation was observed between IgG1 and IgG4
$(\mathrm{R}=0.506 ; \mathrm{P}<0.0001)$, and between $\mathrm{IgG} 3$ and $\mathrm{IgG} 4(\mathrm{R}=0.570$; $\mathrm{P}<0.001$; Fig. 3). When Th1-asssociated antibodies were compared with Th2-associated antibodies, the highest correlation was observed between $\operatorname{IgG} 2$ and $\mathrm{IgG} 4$, with a strong positive correlation coefficient of 0.808 ( $\mathrm{P}<0.0001$; Fig. 3).

Analysis of overall survival. The median survival time after vaccination was 211 days (range, 88-509 days). All 12 cases were classified as cause-specific cases of mortality (Table I).

In terms of Th1-associated antibodies, IgG1, IgG2 and $\mathrm{IgG} 3$, the survival rate for positive patients $(\mathrm{IgG} 1, \mathrm{n}=9$; $\operatorname{IgG} 2$, $\mathrm{n}=5 ; \operatorname{IgG} 3, \mathrm{n}=7$ ) was not significantly higher compared with negative patients (Fig. 4). In terms of Th2-associated antibodies, IgG4 and IgE, no significant difference in survival time was observed between IgG4 positive $(n=8)$ and negative patients. However, for IgE, the survival rate for positive patients $(n=2)$ was significantly lower compared with negative patients ( $\mathrm{P}=0.0116$; Fig. 4).

Evaluation of therapeutic effect based on the mRECIST classification. The evaluation of therapeutic effect based on the mRECIST classification identified no cases of complete response or partial response. There were 5 cases of progressive disease (PD) and 7 cases of stable disease (SD).

No significant association was identified between the presence or absence of positive conversion of $\mathrm{IgG}$ subclasses and $\mathrm{IgE}$ on the one hand, and the therapeutic effect evaluated using 

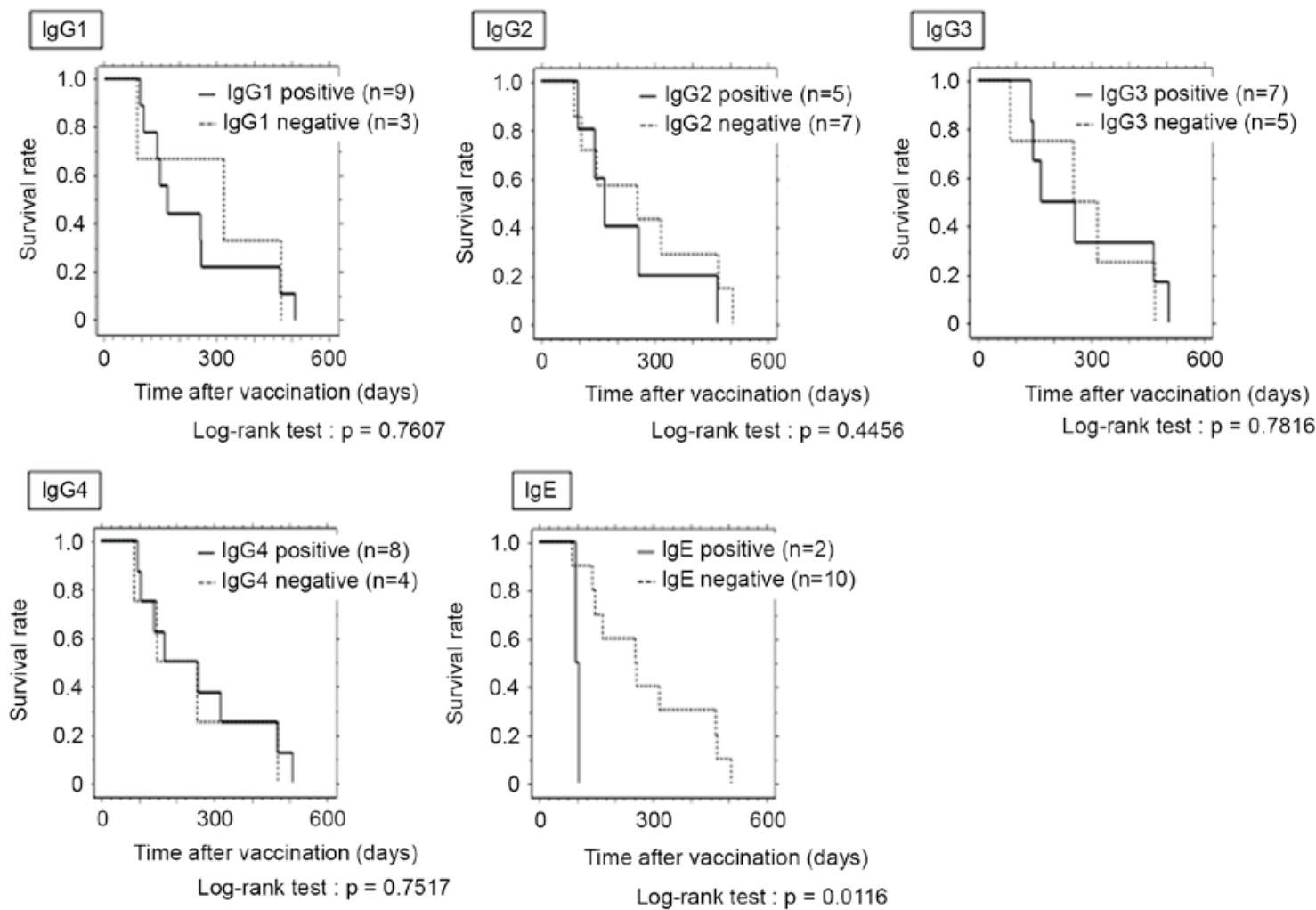

Figure 4. Analysis of overall survival. The survival time of the group with IgE induction was significantly shorter compared with the survival time of the group without IgE induction.

the mRECIST on the other (data not shown). There was also no association between baseline positive cases and therapeutic effect evaluated using the mRECIST (data not shown).

\section{Discussion}

The clinical efficacy of therapeutic cancer vaccines has not been sufficiently demonstrated to date (19-21). According to the RECIST criteria, which are used to evaluate the pre- and post-treatment effect on tumor regression, the majority of cases are classified as SD or PD (19-21). On the other hand, traditional biomarkers of antitumor efficacy are not necessarily reliable indicators in immunotherapy. In immunotherapy, cases have been reported where a decrease in lesion size was observed when therapy was continued despite the appearance of a new lesion with PD classification (22). Therefore, biomarkers, including the immune-related response criteria (19), which does not give a PD classification when new lesions appear alone and which evaluates the sum of the longest diameters of measurable lesions, have emerged (22). Since therapeutic efficacy cannot be determined through imaging at present, the ideal approach is to estimate the therapeutic efficacy of cancer vaccines using biomarkers, including the antigen-specific cellular immune response [whether there is an induction of antigen-specific cytotoxic T lymphocytes (CTL)] and the antigen-specific humoral immune response (production of antigen-specific antibodies), in order to select cases with favorable responses to the treatment. Since tumor cells are directly impaired by CTL, and antibodies have an auxiliary function, ideally an assessment of the antigen-specific cellular immune response should be conducted. However, there is currently no universal standard for the detection of antigen-specific cellular immune response by enzyme-linked immunospot, intracellular cytokine and HLA-multimer staining methods. Furthermore, there is a problem of low repeatability and sensitivity, as well as extensive issues associated with inter-laboratory validation (23). By contrast, measurement methods for antigen-specific humoral immune responses, including ELISA and Luminex assays, are well established, and the problems of repeatability and sensitivity can be resolved. There are pros and cons to using antigen-specific cellular immune responses and antigen-specific humoral immune responses as biomarkers of cancer vaccines. However, in the present study, repeatability and sensitivity were given priority and therefore antigen-specific humoral immune response was used for the evaluation

When the induction of humoral immunity after vaccination was investigated in the present study, the positive conversion rates of Th1-associated antibodies IgG1, IgG2 and IgG3 were $75 \%(9 / 12), 41.7 \%(5 / 12)$ and $58.3 \%$ (7/12), respectively. These values indicated high rates of induction. By contrast, the positive conversion rates of the Th2-associated antibodies, IgG4 and $\mathrm{IgE}$, were $66.7 \%(8 / 12)$ and $16.7 \%$ (2/12), respectively.

Previously, the current authors reported that a type III allergic reaction is triggered when there is an excessive induction of antigen-specific immunity with a cancer vaccine (12). When Th1-associated antibodies are excessively induced, there is a possible shift from a Th1-biased cytokine environment to a Th2-biased cytokine environment (12). In the present study, the comparison of Th1-asssociated antibodies revealed the strongest correlation between IgG1 and $\mathrm{IgG} 3$, with a correlation coefficient of $\mathrm{R}=0.686(\mathrm{P}<0.0001)$. Th1 and Th2 cells are 
known to suppress and balance each other. Th1 cells secrete IFN $\gamma$ and activate inflammatory pathways, while Th2 cells secrete IL-4 and IL-5, which upregulate antibody formation. Therefore, Th1 cells and Th2 cells are able to cross-inhibit each other (24); the results of the present study revealed a strong positive correlation between the Th1-associated antibody IgG2 and the Th2-associated antibody IgG4, with a correlation coefficient of $\mathrm{R}=0.808(\mathrm{P}<0.0001)$. Th2-associated antibody $\mathrm{IgG} 4$ may be induced in direct proportion to the degree of induction of Th1-associated antibody IgG2.

When the association between increased antibody levels and survival time was examined for the vaccination in the present study, no significant difference in survival time was observed between patients with $\geq 1$ induced Th1-associated antibody and patients without induction. Although an antigen-specific immune reaction was triggered, survival time was not affected due to the following: i) Sufficient therapeutic effect was not observed since an antigen-specific CTL was not induced in spite of the induction of an antigen-specific humoral immune response; and ii) target patients had unresectable advanced recurrent cancers and controlling their condition with immunotherapy alone may have been difficult from the start.

By contrast, the survival time of the patients in which the Th2-associated antibody IgE was induced was significantly shorter compared with the survival time of patients without IgE induction. Previous studies of IgE levels and tumors have reported a negative correlation between past history of allergies and various cancers (25-27). From a molecular biology perspective, the antitumor effect of antigen-specific IgE antibodies has been demonstrated in vivo and in vitro (28-35). Since its effect is known to be stronger and to last for a longer period of time compared with $\mathrm{IgG}$, IgE immunotherapy has gained acceptance as a new concept in cancer treatment (28-35). This idea conflicts with the current findings and the authors intend to investigate the cause of the discrepancy in the future. A study has reported on the association between induction of antigen-specific $\mathrm{IgE}$ in cancer immunotherapy of humans and survival rate (36). When the survival rate of colorectal cancer patients vaccinated with a recombinant carcinoembryonic antigen protein was examined, there was a significant positive improvement in survival rate in the group with IgA antibody induction, even though the presence or absence of IgE antibody induction did not affect the survival rate (36). Future studies will involve additional investigation using IgA fractions. The present study, a clinical trial of CHP-MAGE-A4 cancer vaccine, does not explain whether survival time was shortened as a result of $\mathrm{IgE}$ induction or whether $\operatorname{IgE}$ is induced when life expectancy is short. However, the results of the present study suggest that caution is required when antigen-specific $\operatorname{IgE}$ responses are observed during cancer vaccination therapy.

In the present study, no significant difference in survival time was observed between patients with Th2-associated IgG4 antibody induction and patients without IgG4 induction. IgG4 is the least abundant IgG subclass in healthy adult serum, accounting for $\sim 3 \%$ of the total $\operatorname{IgG}$ level $(37,38)$. It is primarily induced as a response to chronic antigen stimulation and inflammation (39). It is also associated with immunological tolerance under chronic antigen stimulation as exemplified by the desensitization therapies used for allergies (39). From the perspective of antitumor immunity, IgG4 and $\mathrm{IgE}$ are known to inhibit the antitumor effect (40). In fact, previous studies have indicated an association between the elevation of serum IgG4 levels and an unfavorable prognosis of biliary cancer and malignant melanomas (41-43). The adverse effect of IgG4 antibodies on antitumor immunity could not be confirmed based on the survival curve from the present study. In terms of association between the induction of a humoral response and the clinical response, the current data did not reveal any significant associations, including $\operatorname{IgG}, \operatorname{IgG}$ subclass, $\operatorname{IgE}$ and baseline positivity.

Jäger et al (44) reported in a clinical trial utilizing NY-ESO1 that baseline positivity of the antigen-specific antibody affected patient survival. The presence of anti-MAGE-A4 antibodies prior to MAGE-A4 cancer vaccination is likely to depend on background factors such as the history and duration of chemotherapy and radiotherapy before enrollment in the clinical trial. Also, prognosis may be affected by the immune environment of the advanced cancer patients. According to data from the present study, the presence or absence of baseline antibodies does not affect prognosis. Further investigation is required to clarify the influence of baseline antibody on prognosis by examining more cases with additional study variables, including pretreatment and suppressor cells.

Further study is warranted that should be based on addressing the limitations of this study; these include analysis of an increased number of patients, and additional data regarding the elicited specific $\mathrm{T}$ cell response and immune suppressor cells.

In conclusion, the results of the present study suggest that, in patients who have been vaccinated with the CHP-MAGE-A4 cancer vaccine, it may be possible to predict the induction of Th2-associated antibody IgG4 by monitoring Th1-associated antibody $\operatorname{IgG} 2$, and that serum $\operatorname{IgE}$ response may be a marker for an unfavorable prognosis.

\section{References}

1. Boon T, Coulie PG, Van den Eynde BJ and van der Bruggen P: Human $\mathrm{T}$ cell responses against melanoma. Annu Rev Immunol 24: 175-208, 2006.

2. Rosenberg SA: Progress in human tumour immunology and immunotherapy. Nature 411: 380-384, 2001.

3. Rosenberg SA, Yang JC and Restifo NP: Cancer immunotherapy: Moving beyond current vaccines. Nat Med 10: 909-915, 2004.

4. Oba K, Teramukai S, Kobayashi M, Matsui T, Kodera Y and Sakamoto J: Efficacy of adjuvant immunochemotherapy with polysaccharide $\mathrm{K}$ for patients with curative resections of gastric cancer. Cancer Immunol Immunother 56: 905-911, 2007.

5. Takeoka T, Nagase H, Kurose K, Ohue Y, Yamasaki M, Takiguchi S, Sato E, Isobe M, Kanazawa T, Matsumoto M, et al: NY-ESO-1 protein cancer vaccine with poly-ICLC and OK-432: Rapid and strong induction of NY-ESO-1-specific immune responses by poly-ICLC. J Immunother 40: 140-147, 2017.

6. Hoon DS, Yuzuki D, Hayashida M and Morton DL: Melanoma patients immunized with melanoma cell vaccine induce antibody responses to recombinant MAGE-1 antigen. J immunol 154: 730-737, 1995.

7. Noguchi M, Mine T, Komatsu N, Suekane S, Moriya F, Matsuoka K, Yutani S, Shichijo S, Yamada A, Toh U, et al: Assessment of immunological biomarkers in patients with advanced cancer treated by personalized peptide vaccination. Cancer Biol Ther 10: 1266-1279, 2010. 
8. Yoshida K, Noguchi M, Mine T, Komatsu N, Yutani S, Ueno T, Yanagimoto H, Kawano K, Itoh K and Yamada A: Characteristics of severe adverse events after peptide vaccination for advanced cancer patients: Analysis of 500 cases. Oncol Rep 25: 57-62, 2011.

9. Romagnani S: TH1 and TH2 in human diseases. Clin Immunol Immunopathol 80: 225-235, 1996.

10. Shaw DR, Khazaeli MB and LoBuglio AF: Mouse/human chimeric antibodies to a tumor-associated antigen: Biologic activity of the four human IgG subclasses. J Natl Cancer Inst 80: 1553-1559, 1988.

11. Oken MM, Creech RH, Tormey DC, Horton J, Davis TE, McFadden ET and Carbone PP: Toxicity and response criteria of the Eastern Cooperative Oncology Group. Am J Clin Oncol 5: 649-655, 1982

12. Kyogoku N, Ikeda H, Tsuchikawa T, Abiko T, Fujiwara A, Maki T, Yamamura Y, Ichinokawa M, Tanaka K, Imai N, et al Time-dependent transition of the immunoglobulin $\mathrm{G}$ subclass and immunoglobulin E response in cancer patients vaccinated with cholesteryl pullulan-melanoma antigen gene-A4 nanogel. Oncol Lett 12: 4493-4504, 2016.

13. Hoos A, Parmiani G, Hege K, Szno M, Loibner H, Eggermont A Urba W, Blumenstein B, Sacks N, Keilholz U, et al: A clinical development paradigm for cancer vaccine and related biologics. J Immunother 30: 1-15, 2007.

14. Aoki M, Ueda S, Nishikawa H, Kitano S, Hirayama M, Ikeda H, Toyoda H, Tanaka K, Kanai M, Takabayashi A, et al: Antibody responses against NY-ESO-1 and HER2 antigens in patients vaccinated with combinations of cholesteryl pullulan (CHP)-NY-ESO-1 and CHP-HER2 with OK-432. Vaccine 27 6854-6861, 2009.

15. Kageyama S,Kitano S,HirayamaM,Nagata Y,Imai H,ShiraishiT, Akiyoshi K, Scott AM, Murphy R, Hoffman EW, et al: HUmoral immune responses in patients vaccinated with 1-146 HER2 protein complexed with cholesteryl pullulan nanogel. Cancer Sci 99: 601-607, 2008.

16. Kageyama S, Wada H, Muro K, NIwa Y, Ueda S, Miyata $H$ Takiguchi S, Sugino SH, Miyahara Y, Ikeda H, et al: Dose-dependent effects of NY-ESO-1 protein vaccine complexed with cholesteryl pullulan (CHP-NY-ESO-1) on immune responses and survival benefits of esophageal cancer patients. J Transl Med 11: 246, 2013

17. Gu XG, Schmitt M, Hiasa A, Nagata Y, Ikeda H, Sasaki Y, Akiyoshi K, Sunamoto J, Nakamura H, Kuribayashi K and Shiku H: A novel hydrophobized polysaccharide/oncoprotein complex vaccine induces in vitro and in vivo cellular and humoral immune responses against HER2-expressing murine sarcoma. Cancer Res 58: 3385-3390, 1998.

18. Hsu SM, Raine L and Fanger H: The use of antiavidin antibody and avidin-biotin-peroxidase complex in immunoperoxidase technics. Am J Clin Pathol 75: 816-821, 1981.

19. Goydos JS, Elder E, Whiteside TL, Finn OJ and Lotze MT: A phase I trial of a synthetic mucin peptide vaccine. Induction of specific immune reactivity in patients with adenocarcinoma. J syrg Res 63: 298-304, 1996.

20. Miyagi Y, Imai N, Sasatomi T, Yamada A, Mine T, Katagiri K, Nakagawa M, Muto A, Okouchi $\mathrm{S}$, Isomoto $\mathrm{H}$, et al: Induction of cellular immune responses to tumor cells and peptides in colorectal cancer patients by vaccination with SART3 peptides. Clin Cancer Res 7: 3950-3962, 2001.

21. Tsuruma T, Hata F, Torigoe T, Furuhata T, Idenoue S, Kurotaki T, Yamamoto M, Yagihashi A, Ohmura T, Yamaguchi K, et al: Phase I clinical study of anti-apoptosis protein, survivin-derived peptide vaccine therapy for patients with advanced or recurrent colorectal cancer. J Transl Med 2: 19, 2004

22. Wolchok JD, Hoos A, O'Day S, Weber JS, Hamid O, Lebbé C, Maio M, Binder M, Bohnsack O, Nichol G, et al: Guidelines for the evaluation of immune therapy activity in solid tumors: Immune-related response criteria. Clin Cancer Res 15: 7412-7420, 2009

23. Janetzki S, Britten CM, Kalos M, Levitsky HI, Maecker HT, Melief CJ, Old LJ, Romero P, Hoos A and Davis MM 'MIATA'-minimal information about $\mathrm{T}$ cell assays. Immunity 31 : 527-528, 2009

24. Kidd P: Th1/Th2 balance: The hypothesis, its limitations, and implications for health and disease. Altern Med Rev 8: 223-246, 2003.

25. Turner MC, Chen Y, Krewski D, Ghadirian P, Thun MJ and Calle EE: Cancer mortality among US men and women with asthma and hay fever. Am J Epidemiol 162: 212-221, 2005.
26. Wang $\mathrm{H}$ and Diepgen TL: Is atopy a protective or a risk factor for cancer? A review of epidemiological studies. Allergy 60: 1098-1111, 2005.

27. Turner MC, Chen Y, Krewski D and Ghadirian P: An overview of the association between allergy and cancer. Int J Cancer 118 3124-3132, 2006.

28. Nagy E, Berczi I and Sehon AH: Growth inhibition of murine mammary carcinoma by monoclonal IgE antibodies specific for the mammary tumor virus. Cancer Immunol Immunother 34 63-69, 1991

29. Kershaw MH, Darcy PK, Trapani JA, MacGregor D and Smyth MJ: Tumor-specific IgE-mediated inhibition of human colorectal carcinoma xenograft growth. Oncol Res 10: 133-142, 1998.

30. Gould HJ, Mackay GA, Karagiannis SN, O'Toole CM, Marsh PJ, Daniel BE, Coney LR, Zurawski VR Jr, Joseph M, Capron M, et al: Comparison of $\operatorname{IgE}$ and $\operatorname{IgG}$ antibody-dependent cytotoxicity in vitro and in a SCID mouse xenograft model of ovarian carcinoma. Eur J Immunol 29: 3527-3537, 1999.

31. Reali E, Greiner JW, Corti A, Gould HJ, Bottazzoli F, Paganelli G, Schlom J and Siccardi AG: IgEs targeted on tumor cells: Therapeutic activity and potential in the design of tumor vaccines. Cancer Res 61: 5517-5522, 2001.

32. Riemer AB, Untersmayr E, Knittelfelder R, Duschl A, Pehamberger H, Zielinski CC, Scheiner O and Jensen-Jarolim E: Active induction of tumor-specific IgE antibodies by oral mimotope vaccination. Cancer Res 67: 3406-3411, 2007.

33. Jensen-Jarolim E, Achatz G, Turner MC, Karagiannis S, Legrand F, Capron M, Penichet ML, Rodríguez JA, Siccardi AG, Vangelista L, et al: AllergoOncology: The role of IgE-mediated allergy in cancer. Allergy 63: 1255-1266, 2008.

34. Singer J and Jensen-Jarolim E: IgE-based immunotherapy of cancer: Challenges and chances. Allergy 69: 137-149, 2014.

35. Josephs DH, Spicer JF, Karagiannis P, Gould HJ and Karagiannis SN: IgE immunotherapy: A novel concept with promise for the treatment of cancer. MAbs 6: 54-72, 2014.

36. Staff C, Magnusson CG, Hojjat-Farsangi M, Mosolits S, Liljefors M, Frodin JE, Wahrén B, Mellstedt H and Ullenhag GJ: Induction of IgM, IgA and IgE antibodies in colorectal cancer patients vaccinated with a recombinant CEA protein. J Clin Lmmunol 32: 855-865, 2012.

37. Schur PH: IgG subclasses. A historical perspective. Monogr Allergy 23: 1-11, 1988.

38. Vidarsson G, Dekkers $\mathrm{G}$ and Rispens $\mathrm{T}$ : $\mathrm{IgG}$ subclasses and allotypes: From structure to effector function. Front Immunol 5: 520,2014

39. Shamji MH, Ljørring C, Francis JN, Calderon MA, Larché M, Kimber I, Frew AJ, Ipsen H, Lund K, Würtzen PA and Durham SR: Functional rather than immunoreactive levels of IgG4 correlate closely with clinical response to grass pollen immunotherapy. Allergy 67: 217-226, 2012

40. Crescioli S, Correa I,Karagiannis P,Davies AM,Sutton BJ,Nestle FO and Karagiannis SN: IgG4 characteristics nad functions in cancer immunity. Curr Allergy Asthma Rep 16: 7, 2016.

41. Karagiannis P, Gilbert AE, Josephs DH, Ali N, Dodev T, Saul L, Correa I, Roberts L, Beddowes E, Koers A, et al: IgG4 subclass antibodies impair antitumor immunity in melanoma. J Clin Invest 123: 1457-1474, 2013.

42. Karagiannis P, Villanova F, Josephs DH, Correa I, Van Hemelrijck M, Hobbs C, Saul L, Egbuniwe IU, Tosi I, Ilieva KM, et al: Elevated IgG4 in patient circulation is associated with the risk of disease progression in melanoma. Oncoimmunology 4: e1032492, 2015.

43. Harada K, Shimoda S, Kimura Y, Sato Y, Ikeda H, Igarashi S, Ren XS, Sato H and Nakanuma Y: Significance of immunoglobulin G4 (IgG4)-positive cells in extrahepatic cholangiocarcinoma: Molecular mechanism of IgG4 reaction in cancer tissue. Hepatology 56: 157-164, 2012.

44. Jäger E, Gnjatic S, Nagata Y, Stockert E, Jäger D, Karbach J, Neumann A, Rieckenberg J, Chen YT, Ritter G, et al: Induction of primary NY-ESO-1 immunity: CD8+ T lymphocyte and antibody responses in peptide-vaccinated patients with NY-ESO-1+ cancers. Proc Natl Acad Sci USA 97: 12198-12203, 2000

This work is licensed under a Creative Commons Attribution-NonCommercial-NoDerivatives 4.0 International (CC BY-NC-ND 4.0) License. 